\title{
Arquivo, memória e acontecimento em uma política de Fundos Documentais
}

Amanda E. Scherer (Corpus/DLCL/PPGL/UFMS) Simone de Mello de Oliveira (Corpus/PPGL/PNPD-CAPES/UFSM)

Verli Petri (Corpus/DLV/PPGL/UFSM) Zélia Maria Viana Paim (Corpus/PPGL/PNPD-CAPES/UFSM)

\section{Resumo}

O objetivo deste artigo é apresentar resultado de pesquisa realizada pelos integrantes do Laboratório de Fontes de Estudo da Linguagem - Corpus/ PPGL/UFSM, a qual tem como objeto a política de arquivo para Fundos Documentais. A experiência aqui relatada é a criação do Fundo Documental Neusa Carson, uma importante linguista para a constituição disciplinar dos estudos da linguagem no contex to brasileiro. Os conceitos nodais mobilizados são arquivo, memória e acontecimento na relação da Análise de Discurso com História das Ideias Linguísticas.

Palavras-chave: arquivo; memória; acontecimento; política; Fundos Documentais. 


\section{Nossa história nos Estudos da Linguagem}

O retorno do arquivo abre então à análise de discurso possibilidades múltiplas.

GUILHAUMOU \& MALDIDIER

Nos últimos tempos temos produzido trabalhos, de forma intensa, enquanto pesquisadores do Laboratório CORPUS, sobre a constituição da história disciplinar moderna e, principalmente, sobre a história da Linguística no sul. São teses, dissertações, artigos científicos e obras de referência, interessantes do ponto de vista da produção do conhecimento, e isso se dá em parceria com pesquisadores de diferentes instituições brasileiras e estrangeiras. Boa parte dos trabalhos procura refletir sobre como tal história pode ter a sua versão na contemporaneidade e, ao mesmo tempo, como ela se constitui no âmbito regional, nacional e no quadro dos países do Prata. Tal ação se dá através de documentos/arquivos/acervos que estamos reunindo e recuperando em nosso Laboratório, servindo para consulta e disponibilizados em redes de saberes através da nova política ditada pela (re)documenta(ri-

Nos referimos ao projeto "Linguística no Sul: estudo das ideias e organização da memória" - Primeira etapa, CNPq, bolsa de Produtividade, 2000.

2 Recebemos, também, o arquivo pessoal e o acervo bibliográfico da Profa. Aldema Menine Mckinney (UFSM) das mãos da própria pesquisadora. A referida professora trabalhou, por mais de 10 anos, em Políticas Públicas de Alfabetização em comunidades indígenas em zona de fronteira. Já o de Maria Luiza R. Remédios, professora de Literatura Portuguesa da UFSM e da PUC/ $\mathrm{RS}$, recebemos a doação pelas mãos do seu filho, em solenidade pública, no 08 de agosto de 2012

3 Para a segunda etapa do Projeto de Pesquisa: "Linguística no Sul: estudo das ideias e organização da memória", estamos contando com a participação de três bolsistas em estágio de Pós-Doutorado. Duas vinculadas ao Edital CAPES-PNPD, e uma vinculada ao Edital DOCFIX/FAPERGS/ CAPES. za)ção do mundo, proposta por Pédauque (2007) para que novas leituras possam ser realizadas e produzidas.

Dentro de tal política, estamos construindo, cada vez mais, instrumentos que possibilitem constituir a história disciplinar contemporânea e, nos últimos tempos, estamos concebendo um projeto de criação de um Centro de Documentação e Memória composto por vários setores, entre eles, o de Fundos Documentais e Acervos. O primeiro fundo a ser pensado e criado foi o Fundo Documental Neusa Carson (FNDC), designado pelo nome de uma importante linguista do sul do país, que viveu e trabalhou na UFSM e na PUC/RS nas décadas de 70 e 80, contribuindo para a institucionalização e disciplinarização da Linguística entre nós e tendo uma participação nacional e estrangeira importantíssima no desenvolvimento de pesquisas no campo da descrição de línguas indígenas, mais precisamente o Macuxi, em Roraima.

Tal nome foi recorrente quando da pesquisa levada a cabo no início de $2000^{1}$. Nela conseguimos levantar e identificar discursivamente o lugar de alguns nomes na sistematização e constituição desse disciplinar e, pela visibilidade que tivemos, na ordem regional, via divulgação em mídia impressa e digital, familiares de alguns pesquisadores renomados nos propuseram fazer a doação de arquivos pessoais e bibliográficos ${ }^{2}$. Foi o caso do primeiro fundo e do qual vamos tratar mais adiante como exemplo ${ }^{3}$. Tal política nos conduz a uma leitura discursiva de um arquivo constituído pela sua historicidade, pois veremos que a linguista em questão procura um espaço de formulação e de produção de saber na Linguística que se revela, para a época 
inicial, fortemente interessante, vinculada à descrição e ao estudo das línguas, através de uma relação acadêmica constituída na e pela sociedade científica da qual fez parte.

Veremos, também, através de tal Fundo, a importância de desenvolver pesquisas que contribuam com o processo de recuperação da História do Conhecimento Linguístico no Brasil, seja no tocante à constituição da língua nacional, seja no tocante às línguas que revelam a heterogeneidade constitutiva do sujeito e da história, mas, também, de que forma isto está posto naquilo que Chevalier \& Encrevé (1984) vão designar como História Social da Linguística.

Tal proposta tem nos colocado questões epistemológicas, tendo por eixo central a possibilidade de um trabalho integrando historicidade disciplinar pelo viés do programa de pesquisa, pensado e posto em prática, no Brasil, pelos pesquisadores Eni Orlandi e Eduardo Guimarães, designado como História das Ideias Linguísticas (HIL), com os estudos franceses da História Social da Linguística. Como sabemos, o programa HIL carrega, na sua constituição e formulação, uma filiação materialista, política e ideológica, lugar teórico da análise de discurso brasileira.

Por outro lado, Chevalier \& Encrevé (1984) nos mostram que a História Social da Linguística não é um complemento na História das Ideias, pois, para os autores, ela não viria mostrar o seu conteúdo para afirmar que as verdades científicas são produtos históricos com a razão de que são irredutíveis à história por realidades singulares, mas que elas nos conduzem à prática científica como uma espécie de universo concreto da prática do pesquisador. Na verdade, a estrutura e o funcionamento da prática científica formam uma espécie particular de condições sociais que determinam os produtos sociais. A prática científica é uma prática social (PÊCHEUX, 1995) como qualquer outra, com suas relações de força, seus monopólios, suas lutas internas e externas, seus interesses, onde todas elas vão intervir de uma maneira ou de outra. A prática científica é por natureza um lugar e um espaço de lutas políticas, impondo a cada pesquisador, em função de sua posição-sujeito, um lugar na história do político disciplinar. Para os autores, uma História Social não seria revelada por uma elaboração propriamente científica, mas ela teria o propósito de poder apreender e entender o sistema de posições da prática social acadêmica.

Um outro ponto importante a ser considerado tem a ver com a História Social do pesquisador, fator determinante também para entendermos o seu lugar hoje na prática científica e suas contribuições para o avanço na história da ciência linguística na contemporaneidade. Para nós, História Social está apartada, é claro, dos moldes de um caminho biográfico que normalmente se tem tomado nas ciências em geral. Ela tem nos ajudado a entender de que forma a história da formação do pesquisador 
é um dado importante para entendermos sua produção no/do conhecimento e sua contribuição no processo de divulgação do saber sobre a língua. História das Ideias Linguísticas e História Social da Linguística são postas lado a lado sem que uma tome o lugar da outra. Histórias repletas de memórias e de sujeitos que envolvem um espaço de interlocução, proporcionado pelo trabalho de leitura do arquivo (PÊCHEUX, 1994).

Outro fator importante é a discussão acerca da noção de arquivo e do tratamento que lhe é dado. Os diferentes documentos têm nos mostrado que devemos retomar nossas certezas, que acreditávamos serem definitivas, para melhor interrogarmos os nossos limites. Nosso interesse é tentar, de fato, entender de que forma a produção do conhecimento sobre a língua tem afetado um fazer acadêmico-pedagógico específico ao nosso meio acadêmico, tendo por eixo principal a compreensão das condições de produção do discurso sobre a ciência linguística e sua rede de circulação nos cursos de graduação e pós-graduação no contexto regional.

\section{Nosso pressuposto teórico e analítico}

Refletir sobre arquivo da perspectiva de quem está trabalhando na implementação de fundos documentais e constituição de acervos provoca um importante deslocamento sobre duas noções essenciais ao trabalho do analista de discurso: a noção de arquivo e de tomada de posição-sujeito de quem produz conhecimento sobre a linguagem, levando em conta o funcionamento das noções de acontecimento, história e memória.

A noção de arquivo, constantemente mobilizada em trabalhos em Análise de Discurso e História das Ideias Linguísticas, tem como ponto de partida o dizer de Pêcheux, ou seja, "campo de documentos pertinentes e disponíveis sobre uma questão" (1994, p. 57) e é desse ponto que partimos quando pensamos no necessário deslocamento. Esse deslocamento se dá não só pela mudança de perspectiva em relação ao arquivo, que é uma materialidade simbólica prenhe em sentidos, podendo ser ainda um recorte no interior deste "campo de documentos pertinentes e disponíveis", de que trata Michel Pêcheux, mas também por estar explicitando a singularidade do que é dito, de um modo de dizer, de uma anunciação (no sentido da expressão francesa "faire connaître"), de uma enunciação.

Ao tomarmos assim o arquivo, torna-se necessário refletir sobre a constituição de uma outra (e talvez nova) tomada de posição-sujeito de quem produz conhecimento sobre a linguagem, o que se torna imprescindível quando se trata da implementação de fundos documentais e de constituição de acervos. Há um sujeito pesquisador que olha o arquivo, pensa sobre arquivo, recorta arquivo, analisa arquivo, e este sujeito está num lugar mais ou menos estável, mas em um lugar já dado. As alterações acontecem, então, quando esse sujeito, em decorrência de um acontecimento, 
Estamos fazendo especial referência aos fundos documentais e acervos de pessoas que dedicaram sua vida pessoal e profissional à pesquisa em Letras e Linguística. No caso deste artigo, estamos fazendo especial referência ao Fundo Documental Neusa Carson.

5 Palestra de Profa. Amanda Scherer em reunião de trabalho no LAS/UFF, em 25 de janeiro de 2012.

6 Itálico do autor. muda sua posição em relação ao arquivo e passa a observar empiricamente, a ver arquivo em lugares que antes não via e onde outros ainda não veem. Esse sujeito passa a integrar, de fato, "a partilha do sensível" (RANCIÈRE, 2005), ele toma uma posição diante do que é comumente partilhado, e o que singulariza cada parte como diferente, essa tomada de posição do sujeito, se dá também diante do que foi silenciado por uma aposentadoria ou por um desaparecimento ${ }^{4}$.

Essa mudança de posição aponta para um caminho onde "la politique ne consiste pas à se demander pour qui ou pour quoi on doit mourir, mais pour qui ou pour quoi on doit vivre" (MILNER, 2011, p. 27). A questão que se coloca, neste momento, é: o sujeito que vê a potencialidade de um arquivo, sua incompletude, seu temporário silêncio, é capaz de dar a esse arquivo a possibilidade de "vida", de anunciação, de enunciação? Para responder a esta questão trazemos Scherer (2012) ${ }^{5}$ quando ela afirma que:

para pensar o arquivo, é necessário considerar a relação entre o desejo do sujeito de ter acesso a tudo e o freio institucional que determina o que pode ser lido do arquivo e o que não poderá ser. Ou seja, estamos pensando o âmbito do controle e do político na forma como os arquivos se constituem.

Não se trata de uma tarefa fácil, mas é, sem dúvida, um desafio que seduz e prende o pesquisador. Para nós, é preciso, então, pensar o acontecimento ${ }^{6}$ como esse "ponto de encontro de uma atualidade e uma memória" (PÊCHEUX, 1997, p. 17), considerando que isso pode ser viabilizado pela recuperação de arquivos pessoais e profissionais. Entendemos que é pela produção do sujeito que está "guardada" em diferentes materialidades que se possa promover a anunciação/enunciação daquilo que já foi dito em outro momento e sob condições de produção outras, levando-se em conta que "o novo se situa em outra parte, no retorno do arquivo” (GUILHAUMOU \& MALDIDIER, 1994, p. 181).

Dessa maneira, pensar um fundo documental a partir do trabalho de um pesquisador, que já não é presença constante e produtiva, é sair do lugar de conforto que tantas vezes é lugar seguro para quem parte de um arquivo já organizado; é investir em "maneiras inéditas de sentir" (HAROCHE, 2008) e é ousar dar voz a quem estava calado e que pela organização de um fundo documental passa a falar novamente, produzindo outros sentidos na sua própria história e na história do outro que produz conhecimento na área dos Estudos da Linguagem. Nesse caso, é preciso tomar o arquivo como "une brèche dans le tissu des jours, l'aperçu tendu d'un événement inatendu" (FARGE, 1989, p. 13), posto que o arquivo pode sempre nos surpreender, ele é pleno de documentos.

Já a noção de documento, estamos tomando-a a partir do deslocamento de sentidos que propõe Foucault (1995, p. 8), quando toma o documento enquanto monumento, sendo necessário 
Entendemos que os arquivos são objeto de estudo da História e da Arquivologia, áreas com as quais dialogamos incessantemente, mas não trataremos de tais relações neste artigo. observá-lo não apenas como "rastros isolados deixados pelo homem", mas, sobretudo, como uma massa de elementos passíveis de serem "isolados, agrupados, tornados pertinentes, inter-relacionados, organizados em conjuntos". Para nós, é preciso tomar cada documento que compõe um fundo documental como algo em movimento, disperso e descontínuo, trata-se de um exemplar de discurso que não pode ser observado apenas em sua organização interna, mas sim na relação que o discurso estabelece com a língua, com a história e com a exterioridade que o envolve. Assim sendo, pensar um fundo documental e/ou a constituição de um acervo a partir de um nome, de uma história de vida pessoal e profissional, não é tornar esse sujeito igual a tantos outros que têm um fundo com seu nome; é, ao contrário, dar a ele uma singularidade, é promover a emergência da diferença, da diferença constitutiva da história, da grande História7.

De fato, o acontecimento é constitutivo da história, embora não seja apreendido por ela, pois "ele é apreendido na consistência de enunciados que se entrecruzam em um momento dado" (GUILHAUMOU \& MALDIDIER, 1994, p. 166). Porque pensar historicamente

c'est concevoir le temps politique comme un temps brisé, discontinue, rythmé de crises. C'est penser la singularité des conjonctures et des situations. C'est penser l'événement non comme miracle surgi de rien mais comme historiquement conditionné, comme articulation du nécessaire et du contingent, comme singularité politique. (BENSAÏD, 2011, p. 41)

Para nós, portanto, ao constituir um fundo documental, promovemos um acontecimento enunciativo, mas não vamos tratar aqui da noção de acontecimento vinculada à noção de formação discursiva, porque estamos tratando da interdiscursividade que isso engendra e não cabe a nós o trabalho de regionalização, pois o fundo documental não é regionalizável, os sentidos, dados como evidentes, estão e não estão nele, pois "o sentido sempre pode ser outro" (ORLANDI, 1996, p. 60).

Pensar um fundo documental é, talvez, abrir a possibilidade de que se reconstruam caminhos já percorridos e marcados por acontecimentos discursivos em diferentes pontos da caminhada do pesquisador que dá nome ao fundo. Esse pesquisador, e aqui podemos nomear Neusa Carson, mobiliza saberes de diferentes formações discursivas em diferentes momentos de sua produção acadêmica, o que nos conduz à noção de interdiscurso proposta por Pêcheux (1995, p. 162) enquanto "todo complexo com dominante' das formações discursivas (...) submetido à lei de desigualdade-contradição-subordinação", aceitando, portanto, a complexidade que o processo de constituição do fundo engendra porque, aquilo que foi dito/escrito em outro momento, volta a ecoar. O arquivo, então, refunda um lugar para que o fazer e/ou o 
"savoir faire" do pesquisador volte à enunciação pela anunciação. O sujeito volta a "falar" - a organização do arquivo em Fundo Documental anuncia esse retorno -, passa a produzir sentidos novamente no discurso de outrem, resolvendo parcialmente o problema do silêncio das caixas fechadas, da aposentadoria, da morte do corpo, do desaparecimento.

Orlandi (2010, p. 59), ao tratar dos "silêncios da memória", nos diz que "não há como não considerar o fato de que a memória é feita de esquecimentos, de silêncios. De sentidos não ditos, de sentidos a não dizer, de silêncios e silenciamentos. Os sentidos se constroem com limites. Mas há também limites construídos com sentidos". Com isso, a autora nos mostra que o acontecimento pode ser uma nuances, ficando entre aquele que escapa e aquele que é absorvido (PÊCHEUX, 2010), pois "é como se não tivesse ocorrido, não porque foi absorvido, mas, ao contrário, justamente porque escapa à inscrição na memória" (ORLANDI, 2010, p 60). Para nós, seria uma inscrição na suspensão do tempo, porque os vestígios dos sentidos do acontecimento não inscritos na memória ficam em suspenso, roçando as bordas da memória, adentrando suas fronteiras, aproveitando-se de sua movência.

De fato, para que haja "o retorno ao arquivo", proposto por Guilhaumou e Maldidier (1994), é preciso aceitar o desafio de promover o gesto de organização empírica e especializada de arquivos ainda silenciosos. Esse trabalho é dos arquivistas, dos historiadores, dos analistas de discurso, já numa perspectiva de abertura de possibilidades múltiplas, desde a fundação até as análises que certamente virão. Assim, torna-se urgente a consagração da presença da "materialidade da língua na discursividade do arquivo", considerando que

Entre a materialidade da língua e da história aí se situa para Pêcheux o arquivo. Ao trabalhar com arquivos de textos, o analista de discurso já leva em consideração, portanto, antes de tudo, que tais textos são fatos de língua. E a língua na perspectiva da análise do discurso é capaz de contradições, de jogo com e sobre os sentidos, porque a língua, como sabemos, tem mecanismos de resistência, não é transparente, e não o é porque se inscreve na história. $\mathrm{E}$ isso faz toda a diferença! (ROMÃO; FERREIRA; DELA-SILVA, 2011, p. 13)

Portanto, é preciso fazer a diferença, é preciso lutar pela constituição e manutenção de Fundos Documentais, trata-se de um ato político e, como nos diz Milner (2011, p. 10), "la politique vient incessamment combler les silences de notre société". O que nos leva a sustentar junto com Guilhaumou que

l'archive n'est pas simplement l'ensemble des textes qu'une société a laissés. Matériel brut désormais exploré conjointement par l'historien classique et l'historien du discours, mais à partir duquel l'historien du discours ne privilégie pas la recherche

Itálico da autora. de strutures sociales cachées, elle est alors principalement 
un dispositif non réglé a priori d'énoncés qui constituent des figures, des objets et des concepts distincts. Ainsi chaque dispositif d'archive établit sa propre mise en oeuvre (2006, p. 21).

Assim sendo, pensar em arquivo é estabelecer relações entre o sujeito e a memória. Pierre Nora nos ajuda a tomar o arquivo pelo o que ele designa "lugares de memória" (1993, p. 13), que "nascem e vivem do sentimento que não existe memória espontânea, que é preciso criar arquivos [...] porque essa não é uma ação natural". Para o autor, os "lugares de memória" não existem sem o olhar vigilante da história, ao mesmo tempo em que é nos "lugares de memória" que a história se ancora porque deles se apodera, ao que acrescentamos, por um movimento que os constitui: são momentos recortados na movência da história. Esse movimento pendular memória-história resulta numa sobredeterminação recíproca, pois, como ensina Guilhaumou (1993), o dispositivo experimental precisa ser colocado em prática pela leitura de arquivos porque, antes de qualquer coisa, ele comporta uma parte descritiva, mas inclui nele também elementos reflexivos em uma dimensão interpretativa.

Para nós, os "lugares de memória" pertencem a domínios que atestam sua complexidade constitutiva; simultaneamente, simples e ambíguos, naturais e artificiais, são ofertados à mais sensível experiência, emergindo da mais abstrata elaboração. Pode-se investir um lugar de aparência puramente material, como um depósito de arquivos, como lugar de memória. Mas, para um lugar constituir-se como "lugar de memória", deve existir uma "vontade de memória" que imprima a sua identidade (NORA, 1993 p. 28). Havendo essa vontade de memória, será profícua a constituição de arquivos, garantindo-se espaço para o acontecimento.

Segundo Davallon (2010, p. 25), é preciso que o acontecimento registrado, descrito, representado "saia da indiferença, que ele deixe o domínio da insignificância". O acontecimento deve guardar em si forças para poder impressionar, para poder ser lembrado, para reencontrar sua vida própria no arquivo pelo Fundo Documental, pois, assim, ao ser "memorizado", poderá entrar na história. Enquanto "histórico", poderá se tornar elemento vivo de uma memória.

Importa destacar que entendemos a memória "nos sentidos entrecruzados da memória mítica, da memória social inscrita em práticas, e da memória construída do historiador" (PÊCHEUX, 2010, p. 50), o que certamente é da constituição de um fundo documental, tal como estamos trabalhando. A especificidade de nosso objeto de estudo nos conduz a aceitar que a memória não é e nem poderia ser

uma esfera plena, cujas bordas seriam transcendentais históricos e cujo conteúdo seria um sentido homogêneo, acumulado ao modo de um reservatório: é necessariamente um espaço móvel de divisões, de disjunções, de deslocamentos 
e de retomadas, de conflitos de regularização... Um espaço de desdobramento, réplicas, polêmicas e contra-discursos. (PÊCHEUX, 2010, p. 56).

Entendemos que considerar os acontecimentos na história nos leva a refletir necessariamente sobre o jogo entre a memória e a atualidade. Devemos considerar tanto os acontecimentos que sustentam a estabilidade dos sentidos, os acontecimentos que abalam esses sentidos e aqueles restos de sentido suspensos à deriva, advindos de acontecimentos ainda no domínio da insignificância.

\section{O Fundo Documental Neusa Carson e sua constituição}

Em 20 de agosto de 2011 foi inaugurada uma política de trabalho para a institucionalização do Fundo Documental Neusa Carson no âmbito da Universidade Federal de Santa Maria, tendo por local o Laboratório Corpus - Laboratório de Fontes de Estudo da Linguagem, vinculado ao Programa de Pós-Graduação em Letras da UFSM. No ano de 2012 foi registrado o projeto do Fundo Documental Neusa Carson, sob o número 031241 no Gabinete de Projetos do CAL/UFSM, e uma série de ações foram desenvolvidas e outras projetadas, tais como o início e quase conclusão dos trabalhos de Arranjo e Descrição do conjunto de documentos do FDNC, um número da Coleção Fragmentum que será dedicado ao tema (n. 34, Abr.-Jun. de 2013) e uma exposição científico-acadêmica que está agendada para o mês de outubro de 2013. Com o recebimento das três doações iniciais: Neusa Carson, Maria Luiza Ritzel Remédios e de Aldema Menine Mckinney e com a criação do Acervo Michael Phillips, o Laboratório Corpus, através de seus integrantes, elaborou uma política de fundos documentais que servirá de base para a criação de um Centro de Documentação e Memória, que terá sob sua responsabilidade a guarda desses fundos e de fundos vindouros.

Até o momento, foram elaborados pela equipe arquivística (Pólo Arquivologia) três bases de documentos. São eles: a Listagem dos documentos do Fundo Documental Neusa Carson, A Descrição do Fundo Documental Neusa Carson e O Arquivo do Laboratório Corpus 9 . A Descrição do Fundo Documental Neusa Carson apresenta, em linhas gerais, a área de identificação, a área de contextualização, a área de conteúdo e estrutura, a área de fontes relacionadas, a área de notas, a área de controle da descrição e a área de pontos de acesso e indexação de assuntos. O Arquivo do Laboratório Corpus, sob a forma de arranjo, contempla as seguintes séries (gerais), a saber, Série 1: Identificação Pessoal e Exercício de Cidadania; Série 2: Controle de bens e patrimônios; Série 3: Atividades Profissionais; Série 4: Atividades de Pesquisa, Ensino e Extensão; Série 5: Formação Profissional e Acadêmica; Série 6: Participação em Clubes e Associações; Série 7: Prevenção de Doenças e Tratamento de Saúde; Série 8: Produção literária; Série 9: Publicações na imprensa; Série 10: Aperfeiçoamento e

9 OFundo Documental Neusa Carson contém, em identificação inicial, 454 documentos. 
10 Em torno de 70 documentos do FDNC são escritos em língua inglesa. São correspondências com pesquisadores de Universidades americanas (grande maioria) e europeias, textos, material de eventos, comprovantes, vistos, correspondências administrativas com as universidades onde fez mestrado, doutorado e pós-doutorado, cartas para colegas e amigos, etc. Para trabalhar com esses documentos foi criada uma equipe denominada Pólo Inglês, coordenado pela profa. Daniela do Canto.
Participação em Cursos e Eventos; Série 11: Controle Financeiro; Série 12: Relações Sociais; Série 13: Falecimento e Homenagens Póstumas; série 14: Documentação tridimensional.

Propomo-nos "flanar" sobre algumas questões pertinentes ao movimento que ora nos engajamos. Nesse sentido, olhamos para o procedimento de Arranjo e Descrição, em arquivística, que considera o "ciclo vital" dos arquivos e que são classificados em "corrente, intermediário e permanente" (ROUSSEAU \& COUTURE, 1998). No nosso entender, no uso quotidiano isso é dito de outro modo, quando essas três categorias são transformadas em duas, o que está em uso e o que se deve guardar por qualquer razão e tempo que seja. Diz-se "arquivo vivo" e "arquivo morto". Sendo que o arquivo morto é o que fica vivo, é o que é "permanece" nos arquivos para a história. E é nesse arquivo, permanente, que trabalhamos.

Sabemos, também, que toda instituição possui um arquivo vivo e um arquivo morto. Considerando a possibilidade de alguém querer realizar um levantamento sobre Neusa Carson, até o momento, qual o lugar possível para se encontrar alguns dados e fatos? Pensamos de pronto na internet, via site de buscas e, em outro lugar, na UFSM, seu local de trabalho. Mais especificamente no arquivo morto da UFSM, pois é lá que se encontra sua ficha funcional. Então é lá que encontraremos Neusa (viva). No arquivo morto. Ou no arquivo vivo. Vivo para a história porque, segundo Nunes (2008, p. 90), a "memória institucionalizada tem uma história e é sustentada por certas condições, que quando deixam de vigorar, abalam a estabilidade do arquivo". Nosso interesse é adentrar, ainda que rapidamente, neste arquivo morto/vivo que pode nos dar um pouco do que foi o trabalho de Neusa Carson e pode nos dar a dimensão de sua importância para a constituição da história disciplinar.

\section{Cartografia como vestígio do eu a partir de um lugar do pesquisador}

O Fundo Documental Neusa Carson é composto de extensa correspondência com importantes universidades e pesquisadores brasileiros e estrangeiros ${ }^{10}$, ofícios e memorandos internos - correspondência oficial da UFSM, correspondência com órgãos de fomento, assim como solicitações de auxílio-pesquisa, revistas com artigos publicados, tese de doutorado, certificados de participação em eventos, programas de eventos e de viagens de pesquisa, diploma de doutorado, relatórios (CAPES, CNPq, FUNAI, etc.), fotos, manuscritos, datiloscritos e recortes de jornais variados sobre Neusa.

Para este artigo, escolhemos dois trajetos temáticos, nos inspirando em Guilhaumou (2006), para mostrar um pouco do que estamos tratando. O primeiro, diz respeito à cartografia que 
encontramos a partir dos vários slides preparados para apresentações de conferência e participação em congresso da área e que serviram de base para alguns dos artigos publicados pela linguista. Estamos chamando esse primeiro trajeto temático de Cartografia da língua e de si. São as figura1 e figura 2 (Mapa 1a e Mapa 1b).

Fig. 1 - Mapa $1 a^{11}$

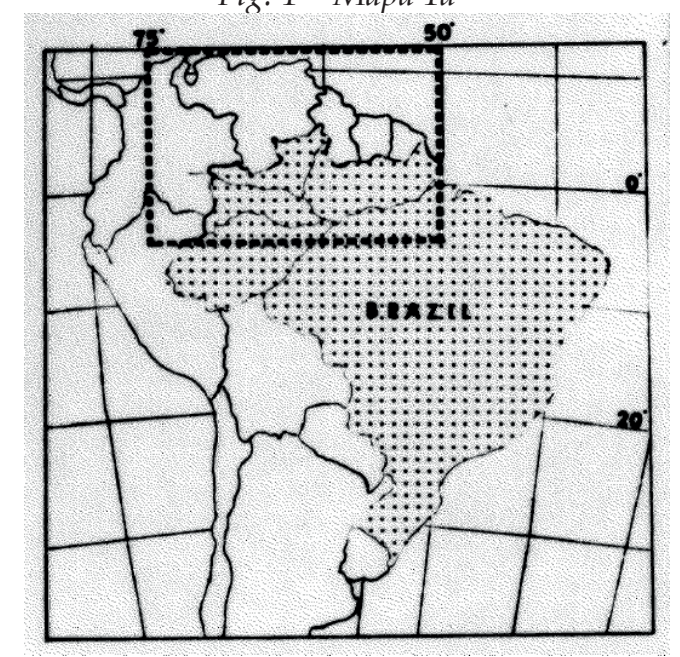

Fig. 2 - Mapa $1 b^{12}$

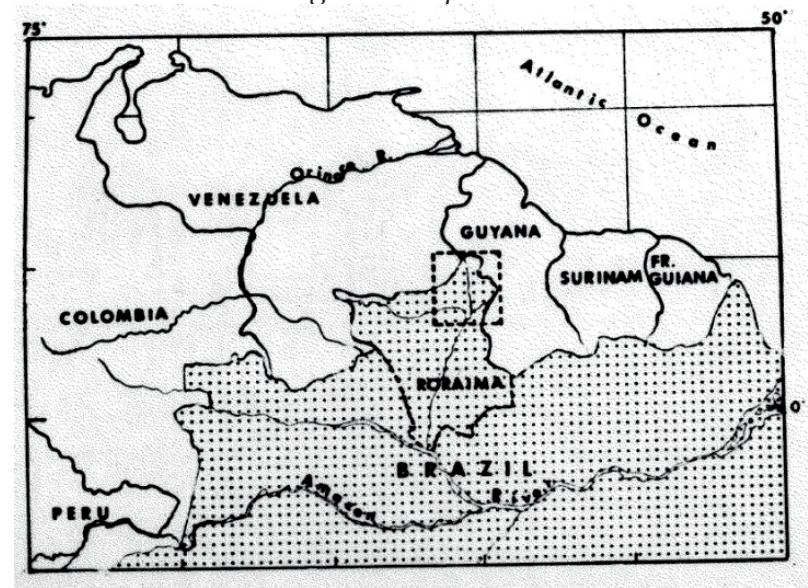

Na figura 1 temos a localização geográfica da comunidade Macuxi (objeto de estudo de Neusa) delineada pelo quadrado tracejado. Já na figura 2, temos o mesmo quadrado tracejado em

11 Fundo Documental Neusa Carson, Série 4 - Atividades de Ensino, Pesquisa e Extensão, Dossiê Pós- Doutorado. Caixa 1, Envelope 74-76. 12 Idem. destaque e a localização geográfica deste espaço em relação ao Brasil e aos demais países do norte da América do Sul.

Já na figura 3, mapa 2, que virá logo a seguir, temos a distribuição das comunidades no espaço e a marcação de quais foram visitadas pela pesquisadora. São elas: Napoleão, Raposa, Vista Alegre e Boa Vista. Todas elas no contexto brasileiro. 


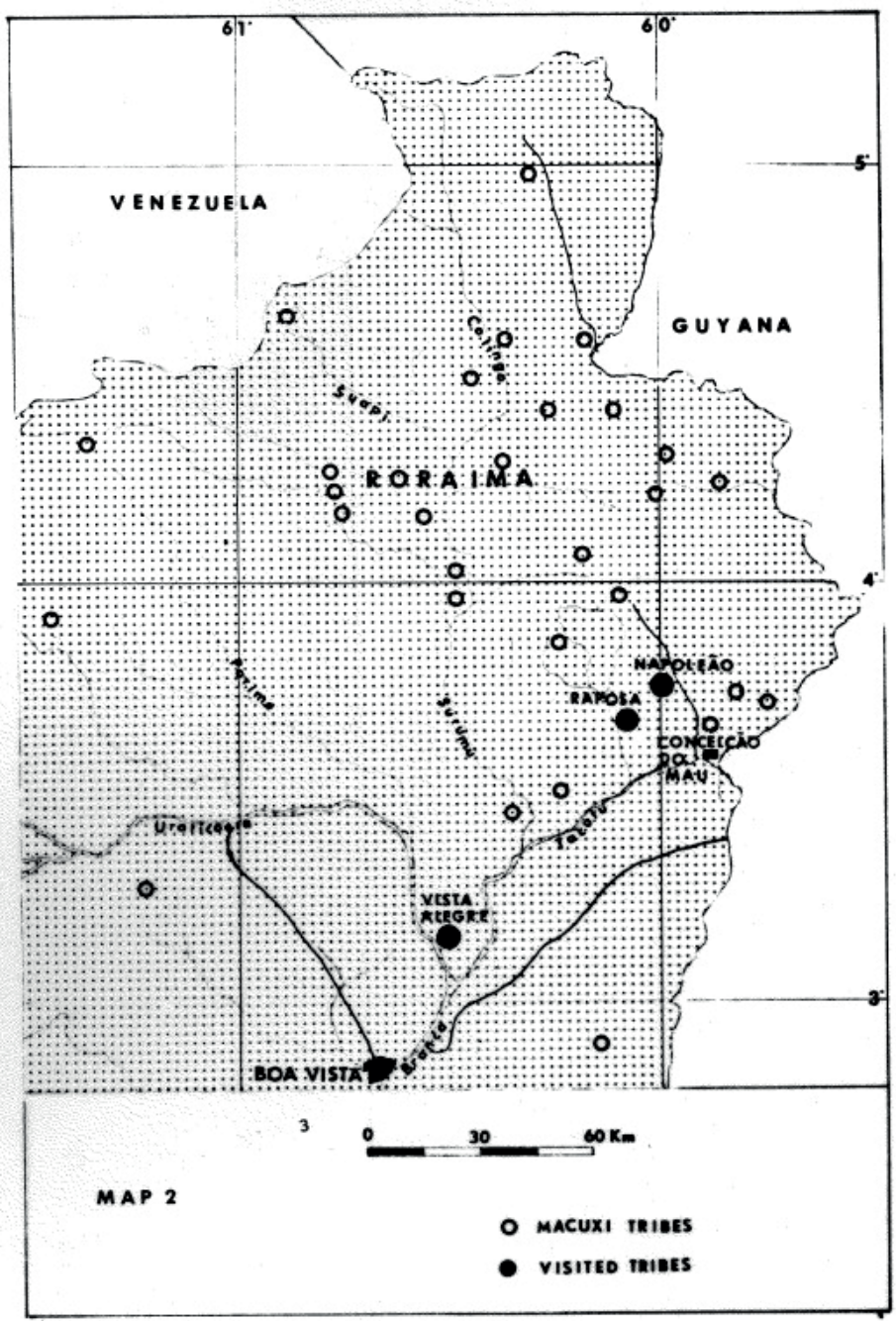

Se tomarmos a cartografia apresentada, veremos que sua extensão territorial não é tão somente física brasileira, mas que a língua dos Macuxi se constitui por uma expansão que ultrapassa as fronteiras meramente territoriais. O que veremos é que o regional ora é nacional e ora ultrapassa as fronteiras brasileiras para regionalizar-se, novamente, do ponto de vista do que designamos, hoje, como América do Sul em relação ao todo no conjunto das Américas. E o desenho dos pontos cardeais vai se reconfigurando também. A linguista do Rio Grande do Sul estudando línguas indígenas de Roraima e que, por sua vez, fazem parte da nação brasileira, nação essa fazendo parte da América do Sul na América do Norte. Para regionalizar-se, outra vez, pela presença da pesquisadora nos Estados Unidos. Um percurso território físico imaginário. Santa Maria. Porto Alegre. Rio de Janeiro. Brasília. Manaus. Napoleão. Raposa. Vista Alegre. Boa Vista. Lawrence. Ohio. Rio de Janeiro. Porto Alegre. Santa Maria. Do particular ao global, do individual ao efeito de totalidade, naquela velha 
problemática para os estudiosos da língua, da língua de dentro e daquela de fora. Da especialista de línguas indígenas, que apresenta no mapa o território da língua Macuxi/indígena/brasileira/ americana numa língua outra, a língua inglesa, que também era sua língua, sua língua de pertença, movendo-se do Brasil para o Brazil, pertencendo lá e cá. É estar numa língua que está dentro e que é de fora, passando a ser de dentro, também pela dupla cidadania da linguista ${ }^{14}$. O que vemos é a necessidade da cartografia também para falar de si, da sua língua, da língua do outro e do outro ainda para se transformar na língua de todos nós.

Aos poucos, vamos entendendo o modo de funcionamento do político, na política de divulgação e de produção do saber sobre a língua(gem). Na verdade, o que vai sendo colocado em cena são as representações da ciência linguística pelo sujeito envolvido nessa história e a mesma cena será, ao nosso ver, a mediadora na/ para uma formação imaginária na história da pesquisa em Letras e Linguística no contexto brasileiro americano.

Já para a figura 4, documento datiloscrito e intitulado como Proposta de pesquisa - descrição sumária (em inglês), vários sãos os possíveis pontos de ancoragem, várias entradas possíveis. Nosso gesto de leitura vai se dar no recorte, a partir das figuras anteriores e que estamos chamando de segundo trajeto temático: Política de línguas e o lugar do linguista. Vejamos o recorte:

Fig. 4 - datiloscrito: Proposta de pesquisa - descrição sumária (em inglês) ${ }^{15}$ e Fig. 5 - anotação de borda de página

14 A professora Neusa Carson era casada com o Prof. William B. Carson. Seu sobrenome de solteira era Martins.

15 Fundo Documental Neusa Carson, Série 4 - Atividades de Ensino, Pesquisa e Extensão, Dossiê Pós-Doutorado. Caixa 3, Envelope 428.

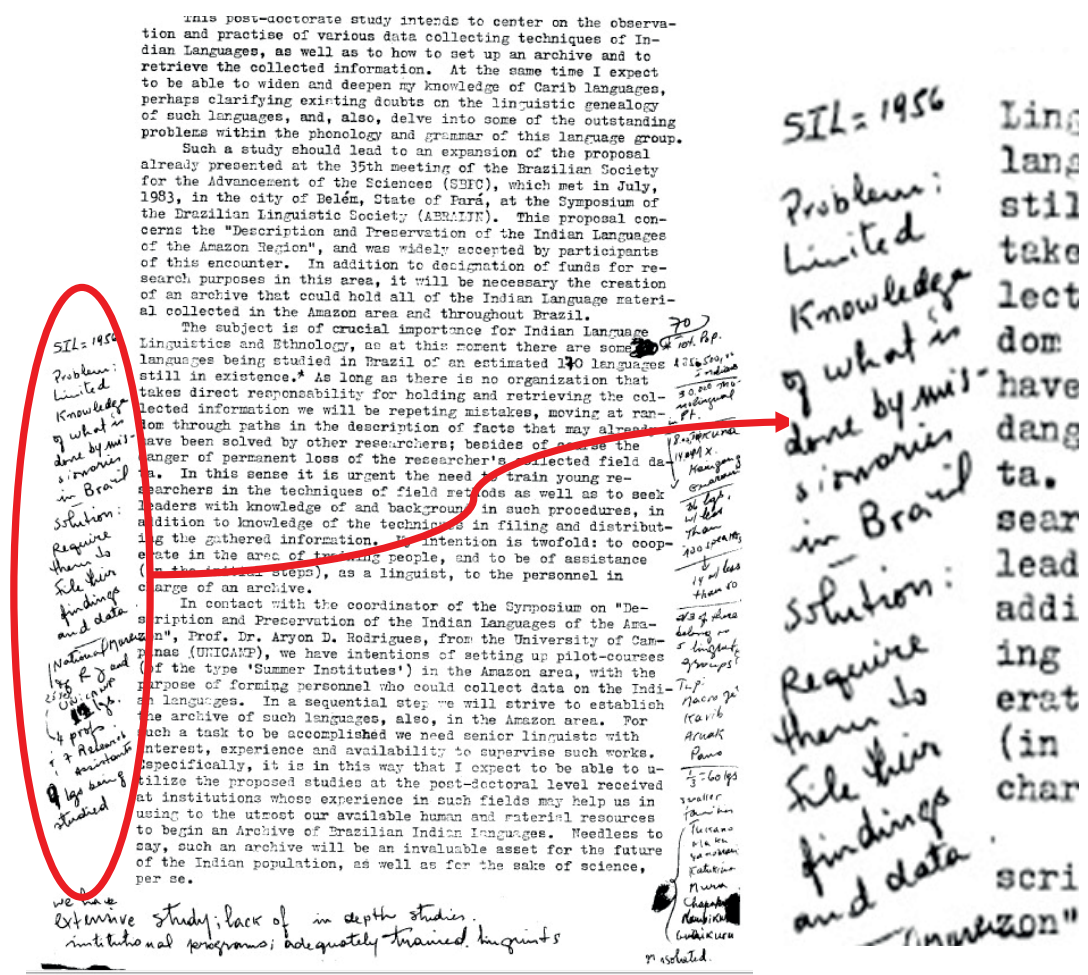




\begin{tabular}{|l|l|}
\hline Transcrição: & Tradução' ${ }^{16}$ \\
SIL = 1956 & SIL $=1956$ \\
Problem: Limited knowledge of what is & Problema: Conhecimento limitado so- \\
done by missionaries in Brazil & bre o que é feito pelos missionários no \\
Solution: Require them to file their find- & Brasil. \\
ings and data. & Solução: Exigir-lhes que apresentem \\
& seus resultados e dados. \\
\hline
\end{tabular}

Todos nós sabemos do lugar político ocupado pelo SIL (Summer Institute of Linguistic) na política da pesquisa brasileira na descrição de línguas indígenas. Não vamos, aqui, entrar nessa problemática. O que queremos trazer para discussão é o lugar que a linguista ocupa e a partir do qual começa a refletir para encontrar o seu lugar na prática da política ${ }^{17}$ do monopólio da política do SIL, pela prática científica. Prática que, na sua constituição, se voltarmos às figuras anteriormente apresentadas, se mostra particular na esfera do nacional regionalizado pelo que somos enquanto americanos no mundo.

Dessa forma, vemos que a análise desses documentos/arquivos tem sua especificidade, internamente, sua ordem discursiva se apoia sobre um escopo institucional, mas ao mesmo tempo particular. Essa ordem é reforçada e reconduzida por toda uma espessura de práticas de dizer e é possível, pela formulação e constituição desse dizer, entender o dizer da disciplina em questão. Mas é possível, também, entender o lugar da Linguística pela maneira como o saber é formulado. Porque "l'archive n'est donc pas une simple matériau où l'on puisse de référents, elle participe d'un geste de lecture où s'actualisent des configurations signifiantes, des dispositifs significatifs" (GUILHAUMOU, 1993, p. 06).

Para nós, esses documentos formam momentos precisos/ preciosos e podemos considerá-los como um acontecimento, na medida em que sua enunciação se inscreve em modos de pertencimento e de relações singulares a cada um e em formulações que excluem outras e traçam caminhos particulares. Esses documentos, postos em uma história disciplinar, formam um lugar preciso/precioso: o lugar da Neusa Carson na história de nossa área particularizando algo de local em nacional, pois como nos ensina Rancière (1994, p. 71), na sua obra Os Nomes da História, são "Esses seres que engajam sobre palavras um destino coletivo" e dessa forma podemos propor questões à relação que a história disciplinar mantém com as palavras desses homens.

\section{Para concluir}

Nossa experiência, ao trabalhar com a História das Ideias Linguísticas no Sul, indicou a urgência de uma retomada estratégica da noção de arquivo e da observação de como ela funciona no

Tradução nossa.

No sentido dado por Rancière em Aux bords du politique (1998). âmbito institucional. Ao iniciarmos esta pesquisa nos deparamos com a ausência de um "lugar de memória" que desse conta da produção acadêmica de professores/pesquisadores que tiveram 
18 Agradecemos, aqui, ao trabalho importante e competente da Profa. Rosani Beatriz Pivetta da Silva, do Curso de Arquivologia de nossa universidade, que faz parte de nossa equipe de pesquisadores e tem contribuído significativamente com o grupo. A referida professora é especialista na área de Arranjo e Descrição. papel fundamental na fundação da Linguística no Brasil, como é o caso de Neusa Carson.

Tudo o que a instituição "guarda" é a sua ficha funcional, somada, às vezes, às lembranças já fragmentadas de colegas e de ex-alunos. Tal realidade tornou urgente a necessidade de se pensar em uma política de fundo documental que possa, de fato, dar conta de uma memória partilhada, ratificada pela oficialidade da história que os documentos promovem. Assim, a criação e a manutenção de fundos documentais vêm funcionar como espaço que reúne séries de documentos de/sobre um pesquisador, mas vêm funcionar, principalmente, como espaço profícuo de acesso a informações antes silenciadas, em suspenso, diríamos nós, promovendo pesquisas mais substanciadas e garantindo a voz daqueles que já não estão mais aqui, mas que tiveram e ainda têm muito a nos dizer.

O que queremos afirmar é que o arquivo, constitutivo do fundo documental, deve ser tomado como acontecimento, a cada momento em que ele retorna, se enuncia, sem esquecer, no entanto, que ele está organizado e descrito por especialistas em arquivo ${ }^{18}$, e eles lhe dão uma ordem própria, reconhecida por estudiosos de todas as áreas. A nosso ver, esta descrição, embora siga preceitos arquivísticos, é sempre outra, posto que "a materialidade do arquivo impõe sua própria lei à descrição" (GUILHAUMOU \& MALDIDIER, 1994, p. 174).

Sendo assim, o que dá ao arquivo o estatuto de acontecimento é o "gesto de interpretação" do analista de discurso, posto que é a partir desse gesto que se recupera uma parte do processo de constituição do arquivo, do fundo documental em questão, por exemplo. Tomar essa posição em relação ao arquivo constitutivo do fundo documental é, também, explicitar relações entre a língua e o arquivo, a história e o arquivo, a instituição e o arquivo, as partes do arquivo com ele mesmo, o discurso e o arquivo.

Por outro lado, o gesto de interpretação do analista leva em conta a história como constitutiva dos sentidos na constituição do arquivo, mas não dá privilégios à história cronológica, toma antes como aliada à memória, visto que a memória é, por sua própria natureza, lacunar e saturada, e por isso permite uma leitura não-linear sem prejuízo às análises propostas.

Acreditamos, de um lado, estar contribuindo para a produção do conhecimento em um domínio de saber que está afetado, também, pela elaboração de instrumentos linguísticos que, por sua vez, vão nos constituindo enquanto sujeitos do conhecimento no emaranhado das relações de fronteira, quer sejam elas de estado ou de países vizinhos no MERCOSUL. Sempre lembrando que vivemos em um espaço de enunciação e de discurso muito marcado pela língua e pela história.

Institucionalmente, por outro lado, estamos cada vez mais imbuídos em um trabalho de equipe e de formação de novos 
pesquisadores com a tarefa, também, de implementarmos uma cultura de pesquisa que ultrapasse a barreira entre os diferentes graus de ensino determinados pelas políticas universitárias por entendermos que o sujeito está sempre instado a interpretar e não depende unicamente de seu estágio de titulação mas, e sobretudo, pelo seu interesse em pesquisa. São tentativas que nos ajudam a refletir sobre a importância da história disciplinar moderna e a constituição da língua enquanto objeto de saber. São tentativas, na sua origem e feitura, ainda embrionárias, mas promissoras do ponto de vista do avanço teórico e analítico para a história brasileira na História das Ideias Linguísticas.

E, em nossa política de arquivo, nossa meta, também, é dar lugar a essa palavra coletiva na criação de um Centro de Documentação e Memória onde estaremos reunindo bibliotecas pessoais, acervos, documentos pessoais de pesquisadores, rascunho de curso e manuscritos de produção de conhecimento. Ou seja, aqueles momentos, fragmentos de um real materializado que não têm nenhuma outra unidade além do nome que lhe damos: Neusa Carson, Aldema Menine Mckinney, Maria Luiza Ritzel Remédios.

E, com a chegada de tais documentos, estamos partilhando com aqueles que o recebem, o veem, ouvem falar deles, o anunciam e depois o "guardam" na memória. Um Centro de Documentação e Memória para que um pedaço do tempo e da memória, posto em pedaços pelo institucional, possa ser partilhado e a partir daí ter sua forma de sobreviver, de ser transmitida, oferecida e depois falada e projetada no tempo do devir fazendo parte da materialidade real da história, dando materialidade futura a algo que teve sua importância pessoal e que pela partilha do sensível (RANCIÈRE, 2005), como temos afirmado, será coletiva. Pois ao guardar o que foi de outrem, estaremos guardando, também, um pouco da história que ajudou a constituir o que somos hoje.

\begin{abstract}
This article aims to present the result of research performed by members of the Laboratorio de Fontes de Estudo da Linguagem - Corpus/ PPGL/UFSM, having as object the file policy for Documentary Funds. The experience reported in this article is the creation of the Neusa Carson Documentary Fund. Carson was an important linguist for the disciplinary constitution of language studies in the Brazilian context. The main concepts used are file, memory, event in relation to Discourse Analysis and History of Linguistic Ideas.
\end{abstract}

Keywords: file; memory; event; policy; documentary fund. 


\section{REFERÊNCIAS}

BENSAID, D. Le spectacle, stade ultime du fétichisme de la marchandise. Paris: Lignes, 2011.

CHEVALIER, J. C. ; ENCREVE, P. Présentation. Langue Française, n. 63. Paris: Larrousse, 1984, p. 3-6.

DAVALLON, J. A Imagem, uma Arte da memória. In: ACHARD, P. et al. Papel da memória. Trad. José Horta Nunes. 3. ed. Campinas: Pontes, 2010. p. 23-32

FARGE, A. Le gôut de l'archive. Paris: Éditions de Seuil, 1989.

FOUCAULT, M. A arqueologia do saber. Trad. Luiz Felipe Baeta Neves. 4. ed. Rio de Janeiro: Forense Universitária, 1995.

GUILHAUMOU, J. A propos de l'analyse de discours. Les historiens et le tournant linguistique. Langages et Société. n. 65, Paris : Editions de la Maison des Sciences de l’Homme, 1993. p. 5-38.

. Discours et événement. L'histoire langagière des concepts. Presses Universitaires de Franche-Comté: Besançon, 2006.

GUILHAUMOU, J.; MALDIDIER, D. Efeitos do arquivo. A análise do discurso do lado da história. Trad. Suzi Lagazzi e José Horta Nunes. In: ORLANDI, E. (Org.) Gestos de leitura. Campinas, SP: Editora da Unicamp, 1994. p. 161-183.

HAROCHE, C. A condição sensiveel: formas e maneiras de sentir no ocidente. Trad. Jacy Alves de Seixas e Vera Avellar Ribeiro. Rio de Janeiro: Contra Capa, 2008.

MILNER, J.-C. Pour une politique des êtres parlants. Paris: Éditions Verdier, 2011.

NORA, P. Entre história e memória: a problemática dos lugares. Trad. Yara Aun Khoury. Revista Projeto História. São Paulo, v. 10, p. 7-28, 1993.

NUNES, J. H. O discurso documental na história das idéias Lingüísticas e o caso dos dicionários. Alfa, São Paulo, v. 52, n. 1, p. 81-100, 2008.

ORLANDI, E. P. Interpretação: autoria, leitura e efeitos do trabalho simbólico. Petrópolis, RJ: Vozes, 1996.

Maio de1968: os silêncios da memória. In: ACHARD, P. et al. Papel da memória. Trad. José Horta Nunes. 3. ed. Campinas: Pontes, 2010. p. 59-71

PÊCHEUX, M. Ler o arquivo hoje. In: ORLANDI, E. et al. (Org.). Gestos de leitura: da história no discurso. Trad. Maria das Graças Lopes Morin do Amaral. Campinas, SP: Editora da Unicamp, 1994. p. 55-66.

Semântica e discurso: uma crítica a afirmação do óbvio.

Trad. Eni P. Orlandi. 2. ed. Campinas, SP: UNICAMP, 1995.

O discurso: estrutura ou acontecimento. Trad. Eni Orlandi. Campinas, SP: Pontes, 1997. 
. Papel da memória. In: ACHARD, P. et al. Papel da memória. Trad. José Horta Nunes. 3. ed. Campinas: Pontes, 2010. p. 49-57. PEDAUQUE. R. T. La redocumentarisation du monde. Toulouse: Cépaduès-Editions, 2007.

RANCIÈRE, J. Os nomes da história: um ensaio poético do saber. Tradução de Eduardo Guimarães e Eni Orlandi. São Paulo: Pontes/ EDUC, 1994.

1998.

. Aux bords du politique, Paris: Gallimard, Coll. Folio Essais,

- A partilha do sensível: estética e política. Trad. Mônica Costa Netto. São Paulo: Editora 34, 2005.

ROMÃO, L. M. S.; FERREIRA, M. C. L.; SILVA, S. D. Arquivo. In: MARIANI, B.; MEDEIROS, V.;SILVA, S. D. (Orgs.). Discurso, arquivo e... Rio de Janeiro: Editora 7 Letras, 2011. p. 11-21.

ROUSSEAU, J-Y; COUTURE, C. Os fundamentos da disciplina arquivística. Trad. Pedro Penteado. Lisboa, Portugal: Nova Enciclopédia, 1998. 